\title{
EFFECTIVENESS OF CONTINUOUS ASSESSMENT FOR MANUAL DRAFTING OF BUILDING DRAWINGS
}

\section{G. W. T. C. KANDAMBY}

Division of Civil Engineering Technology, Institute of Technology, University of Moratuwa, Sri Lanka

ABSTRACT
Drafting manual drawings of building components is one of the learning outcomes in the module of Building
Technology, where students carry out manual drawings as practical work. Students were assessed on manual drawing
together with written questions at the end examination till 2017 in the National Diploma in Technology programme.
Continuous assessment component was introduced as a new method for manual drawing from 2018 and its
effectiveness is evaluated in this study by considering the marks obtained by the students and the students'
perceptions. It is found that there is no significant change in the total marks in this method but almost all students got
through drawing assessment in 2018 and 2019. Students' population of $96 \%$ agreed with the total process of new
method as it supported for them to complete the assigned drawings in time and to gain better performance. More than
$82 \%$ of students agreed that the new method provides a better procedure for carrying out drawing practical with
proper arrangement in the classroom and assists them through feedback. Separating assessment of manual drawing
from end examination and conducting it as a continuous assessment during drawing practical is found to be a
students' friendly method.
KEYWORDS: Drafting drawing, manual drawing, continuous assessment, students' performance, feedback, students'
perception

Received: Jan 02, 2021; Accepted: Jan 22, 2021; Published: Feb 17, 2021; Paper Id.: IJCSEIERDAPR20211

\section{INTRODUCTION}

Building drawings are the most important documents which play the major role of communicating the information among technical personnel regarding the building construction in detail. Construction details are very complex and impossible to present as descriptive form as it may confuse and end up with wrong construction. Therefore understanding construction drawings and drafting drawings are vital while learning building construction technology. Drafting is a language that is used by engineers, draftsmen and other technical people involved in designing to describe the shape and size of the objects (Mark, 1991). Practice has proved that the manual drawing can make students pay more attention to the digestion and application of concept and theory, improve their ability to analyze and solve problems and it results in the cultivation of graphics thinking (Huanyun \& Pan, 2013). Developing skills on drafting building drawing was addressed in the module of Building Construction and Draftsmanship in first year of National Diploma in Technology (NDT) programme conducted by Institute of Technology, University of Moratuwa where drafting building drawings were amalgamated as practical classes. Study was conducted under the title of formative assessments for building drawings by collecting data in the years of 2015, 2016 and 2017 and found that students have developed skill on drafting building drawings but majority of students were not able to get high marks at the end examination (Kandamby, 2019). When comparing the time spent by both students and instructors, the results are not at satisfactory level. But monitoring students' desk work and giving 
feedback for them to understand their mistakes to attend corrections is necessary to facilitate learning environment in the process of drawing practical. With the implementation of semester system to this NDT program in 2018, Continuous Assessment (CA) component has been introduced for this drawing practical and it was managed successfully for last two years (2018 and 2019). Effectiveness of introducing CA of drawing practical in this module is studied as the continuation of the previous study (Kandamby, 2019) by collecting information from 2018 and 2019.

\section{OBJECTIVES OF THE STUDY}

The main objective of this study is to investigate the effectiveness of conducting the practical in manual building drawings and CA in the module of Building Technology I. The specific objectives are to;

- Analyze the marks obtained by the students for manual drafting under previous system in 2015, 2016 and 2017.

- Analyze the marks obtained by the students for CA in manual drafting under the new system in 2018 and 2019.

- Compare the students' performance on drafting manual drawings between the previous method and the new method based on the analysis of 1 and 2 above.

- Investigate the students' perception on carrying out practical on manual drawings and conducting CA through questionnaire.

- Assess the success of conducting CA while performing drawing practical under the new method implemented from 2018.

\section{COURSE MODULE}

Course module considered in this study is Building Technology I in semester I (fifteen weeks) which consists of two hours lecture and three hours manual drawing practical per week for 200 student's batch. There were five learning outcomes in the module and learning outcome relates to this practical is for developing drafting skills of students by attending manual drawings for building components. Through this practical, students are able to draft building drawings, understand the construction details and use the drawings as a language to communicate the information on designed components of buildings. Skill on drafting building drawing is required to draft drawings and sketches which are mostly used in civil engineering construction field and understand the same while using at the field. Aim of the module, its contents, learning outcomes, method of delivery and the assessments were clearly explained to students before commencing the delivery. Continuous assessment and Final Examination (FE) are the two assessments incorporated in this module covering the marks $30 \%$ for CA and balance $70 \%$ for FE.

There were no difficulties to manage and conduct the drawing practical classes within the given period and the continuous assessments were completed prior to ending the semester. Teaching materials for this module were delivered through Moodle and discussions were held during the lecture hours using the power point presentations. Drawing practical classes were conducted for two groups of 100 students (totally for 200 students) with the support of module leader and other four instructors. Attending drawing work is compulsory and students have to show more than $80 \%$ of attendance for these practical classes. There were five drawings which need to be completed during the semester and the arrangement was made to collect and keep the drawn papers in the drawing classroom once the day's work was over. Since the practical was conducted as assessments, students were not allowed to take the drawing papers out of the classroom. Usually three days 
were allocated for the completion of one drawing and thereafter students' performances were evaluated using the marking scheme and recorded the marks in pencil on the drawing paper itself. In addition, corrections were highlighted and clear instruction was given for students to understand their mistakes and attend all corrections in order to complete the drawing in proper standard. Marked drawings can be considered as a form of feedback which supported students to attend the corrections and complete the total drawing. An additional day (three hours) was allocated for final finishing and corrections. Selected three drawings (out of five drawings) were considered for the continuous assessment by informing students in advance and all necessary sketches were provided in the classroom enabling students to attend the drawing without any difficulty. While drafting the drawings in the classroom, instructors assisted students by showing the mistakes and providing necessary details. Student had chances to use relevant sketches or any other additional details they have noted during the lectures or from other sources in order to attend the work satisfactorily.

\section{LITERATURE REVIEW}

There are different forms of assessments. Any form of assessment is required to assess students' learning during the delivering process or after completing the delivery. Classroom assessment plays a very important role in education and there are mainly four reasons for assessing students namely to compare students with each other, to see if students meet a particular standard, to help the student's learning and to check if the teaching programme is doing its job (Baxter, 1997). The effectiveness of assessment may also be evident in the degree to which it motivates students to 'show what they can do' and to devote themselves more completely to learning better so that they can do more (Gardner et al, 2008). Traditional assessment practices are usually good at evaluation but they are often lacking in description and fail to provide students with advice and support to improve their own learning (Brown, 1999). Formative assessment covers the range of informal diagnostic tests a teacher can use to assist the process of learning by his students. Study conducted by Frederickson (1992) in which he emphasized the importance of assessment as a means of developing self-confidence of students. Purpose of CA is that the teacher can continuously assess student's learning outcomes in all three domains namely, cognitive, affective, psychomotor aspects, particularly with regard to knowledge and understanding, procedural knowledge (making comparisons and estimates performing calculations, applying formulas), problem solving and other higher order skills (Mohammad et al, 2017). Assessment is about grading and reporting student achievements and about supporting students in their learning; and CA often does both. Therefore, CA practices generally have a formative function for learning and a summative function for certification (Rosario, 2012). CA has an impact on both the student's results and their methodologies of learning. CA is very good because it takes into account student progression and work throughout the year (Rosario, 2012). Review report of educational quality in developing world (2003) has explained that CA enables pupils to monitor their achievement of grade level goals and to visualize their progress towards those goals before it is too late to achieve them. The results of the study carried out for nine subjects in the Bachelor of Business Administration program at the University of Castilla-La Mancha (Spain) reveals a positive effect of continuous assessment activities on students' academic success (Gonzalez \& Lopez, 2015). It has been emphasized that CA is an ongoing, diagnostic, classroom-based process that uses a variety of assessment tools to measure learner performance (Mweemba \& Chilala, 2007). It was noticed that students put serious effort only on that work of theirs that had effect on their grade; everything else was more or less ignored (Price \& Rust, 2007). Effectiveness of CA can be judged by making observation and collecting information periodically from specific tasks given to students during their learning process (Mohammad et al, 2017). Airasian (1991) reported that continuous assessment as an approach should present the complete number of sources and methods that teacher can apply to collect, interpret and synthesize information about students. Another researcher Nxumalo (2007) 
supports the finding of this study as he has also emphasized on the importance of CA as means of informing educators and learners about the learner's progress which would ultimately benefit the learning process. This finding is also supported by a study conducted by Bayo (2005) who was of the view that CA has the potency to motivating and focusing learner's attention on the lesson. Trotter (2006) claims that CA practices encourage students to learn on an on-going basis. Continuous evaluation activities can be useful instruments for collecting multiple, diverse evidence of students' learning and for providing well-suited educational helps which encourage attainment of learning (Coll et al, 2007). The results of the study carried out by Rosario (2012) indicate that CA is extensively used in the seven departments/sections, either as the only method of assessing undergraduate modules/ courses in Hispanic Studies or, more broadly, combined with examinations. $\mathrm{CA}$ is a regular assessment of the learning performance related to a course module and that is separate from examinations, and accompanied by regular feedback. McDowell et al. (2005) expresses a note of caution about the extensive use of CA with a summative function because it can diminish the provision of effective feedback. The most powerful enhancement to learning is feedback during learning (Biggs \& Tang, 2007). Teaching and learning can be improved by practicing $\mathrm{CA}$ in the classroom and giving feedback to students. CA is part and parcel of instructional process that has to be taken as a key tool in educational quality assurance endeavour (Abejehu, S.B. 2016).

\section{DATA COLLECTION}

\subsection{Students' Performance}

Students' performances of manual drafting under following two methods were collected.

- Previous Method (PM): Eight building components drawings were drafted manually by the students in drawing studio room throughout the year and sat for the end examination. This examination paper consisted of two compulsory drawing questions and four descriptive questions. Students had to answer total five questions within three hours period. Total number of students who sat for the examination was 85 to 100 .

- New Method (NM): Same building component drawings were adjusted to five drawings eliminating uncommon components for the practical of semester I (six month period). After completing the first drawing next three drawings were arranged for the $\mathrm{CA}$ and there were no drafting questions in the final examination. Intake was increased gradually to 120 to 200 .

Marks obtained by the students for the above two methods are tabulated against their index numbers in excel work sheet. There are 3 sets of data (2015, 2016 and 2017) for PM and 2 sets of date (2018 and 2019) for NM. Marks given in PM was out of 40 and the same for NM is out of 30 . All these marks are converted to $100 \%$ and categorized in Table 1 as the number of students achieved the marks under six levels such as marks obtained above 75, 74-65, 64-55, 54-40, 39-25 and below 24.

Table 1: Distribution of marks in manual drawing (out of 100)

\begin{tabular}{|l|c|c|c|c|c|}
\hline & \multicolumn{4}{|c|}{ No. of Students } \\
\hline & \multicolumn{3}{|c|}{ PM } & \multicolumn{2}{c|}{ NM } \\
\hline Marks & 2015 & 2016 & 2017 & 2018 & 2019 \\
\hline$>75$ & 1 & 16 & 9 & 2 & 3 \\
\hline $74-65$ & 2 & 20 & 14 & 10 & 9 \\
\hline $64-55$ & 9 & 19 & 19 & 14 & 30 \\
\hline
\end{tabular}




\begin{tabular}{|l|c|c|c|c|c|}
\hline $54-40$ & 28 & 20 & 30 & 90 & 146 \\
\hline $39-25$ & 38 & 9 & 12 & 0 & 0 \\
\hline$<24$ & 20 & 4 & 4 & 0 & 0 \\
\hline Total & 98 & 88 & 88 & 116 & 188 \\
\hline
\end{tabular}

Students' achievement on manual drawing is one portion of the total assessment and therefore, data for the total marks needs to be considered. Assessment of balance portion is similar in both cases (PM and NM) which are based on the marks obtained from the written questions in yearend / semester end examination. Total marks obtained by the students in 2015,2016, 2017, 2018 and 2019 are entered in the same excel work sheet against their index number and categorized under same levels of marks as in Table 1and presented them in Table 2.

Table 2: Distribution of Total Marks (Manual Drawing + Written Paper)

\begin{tabular}{|l|c|c|c|c|c|}
\hline \multicolumn{5}{|c|}{ Number of Students } \\
\hline \multicolumn{1}{|c|}{ PM } & \multicolumn{2}{c|}{ NM } \\
\hline Marks & 2015 & 2016 & 2017 & 2018 & 2019 \\
\hline$>75$ & 1 & 7 & 3 & 0 & 1 \\
\hline $74-65$ & 2 & 4 & 7 & 6 & 15 \\
\hline $64-55$ & 21 & 12 & 24 & 18 & 42 \\
\hline $54-40$ & 53 & 46 & 41 & 51 & 88 \\
\hline $39-25$ & 12 & 16 & 11 & 35 & 35 \\
\hline$<24$ & 9 & 3 & 2 & 6 & 7 \\
\hline Total & 98 & 88 & 88 & 116 & 188 \\
\hline
\end{tabular}

\subsection{Students' Perception on Manual Drafting and its CA}

Questionnaire survey was conducted to collect information on students' perception on manual drafting and conducting CA from the students who followed this NM in 2019. There were 03 questions related to the procedure of CA, 03 questions for classroom arrangement, 06 questions for students' participation, 07 questions for students' performances and 06 questions for feedback and student-teacher interaction allowing students to rate under the scale of 4 to 1 for strongly agree, agree, neither agree nor disagree and disagree. Sufficient time period (one week) was given for the questionnaire and data was collected from the Moodle analysis importing them in the excel work sheet in order to work out the data as expected. Summary of the data prepared in excel work sheet is presented in Table 6 in Appendix. 


\section{ANALYSIS AND RESULTS}

\subsection{Students' Performance on Manual Drawing}

Number of students who obtained marks for manual drawings at six levels in both PM and NM are shown in Table 1 are converted to percentages of students who obtained marks for manual drawings and presented in Table 4. It is found that all students (100\%) have obtained above pass marks (> 40 marks) in 2018 and 2019 because of the method of conducting CA as it supported students to improve their skills on drafting manual drawing while attending CA in classroom continually. This situation was not in the PM as students had to attend manual drawings under the end examination. Students in 2015 were found very weak in manual drawings compared to 2016 and 2017 in PM.

Table 3: Distribution of marks in manual drawings

\begin{tabular}{|l|c|c|c|c|c|}
\hline \multicolumn{7}{|c|}{ Population of Students as Percentage } \\
\hline \multicolumn{1}{|c|}{ Marks } & $\mathbf{2 0 1 5}$ & $\mathbf{2 0 1 6}$ & $\mathbf{2 0 1 7}$ & $\mathbf{2 0 1 8}$ & $\mathbf{2 0 1 9}$ \\
\hline$>75$ & 1.02 & 18.18 & 10.23 & 1.72 & 1.60 \\
\hline $74-65$ & 2.04 & 22.73 & 15.91 & 8.62 & 4.79 \\
\hline $64-55$ & 9.18 & 21.59 & 21.59 & 12.07 & 15.96 \\
\hline $54-40$ & 28.57 & 22.73 & 34.09 & 77.59 & 77.66 \\
\hline Cumulative $>40$ & 40.82 & 85.23 & 81.82 & 100.00 & 100.00 \\
\hline $39-25$ & 38.78 & 10.23 & 13.64 & 0.00 & 0.00 \\
\hline$<24$ & 20.41 & 4.55 & 4.55 & 0.00 & 0.00 \\
\hline Cumulative $<40$ & 59.18 & 14.77 & 18.18 & 0.00 & 0.00 \\
\hline
\end{tabular}

\subsection{Students' Total Performance}

Students' performances are to be assessed not only considering the marks obtained in manual drawing but also considering the marks obtained at the end examination in NM where students had to answer only for written questions. Total marks presented in Table 2 at six levels are considered and numbers of students who obtained total marks are quantified as percentages and presented in Table 5.

Table 4: Distribution of total marks

\begin{tabular}{|l|c|c|c|c|c|}
\hline \multicolumn{5}{|c|}{ Population of Students as Percentage } \\
\hline \multicolumn{1}{|c|}{ Marks } & $\mathbf{2 0 1 5}$ & $\mathbf{2 0 1 6}$ & $\mathbf{2 0 1 7}$ & $\mathbf{2 0 1 8}$ & $\mathbf{2 0 1 9}$ \\
\hline$>75$ & 1.02 & 7.95 & 3.41 & 0.00 & 0.53 \\
\hline $74-65$ & 2.04 & 4.55 & 7.95 & 5.17 & 7.98 \\
\hline $64-55$ & 21.43 & 13.64 & 27.27 & 15.52 & 22.34 \\
\hline $54-40$ & 54.08 & 52.27 & 46.59 & 43.97 & 46.81 \\
\hline Cumulative $>40$ & 78.57 & 78.41 & 85.23 & 64.66 & 77.66 \\
\hline $39-25$ & 12.24 & 18.18 & 12.50 & 30.17 & 18.62 \\
\hline
\end{tabular}




\begin{tabular}{|l|c|c|c|c|c|}
\hline$<24$ & 9.18 & 3.41 & 2.27 & 5.17 & 3.72 \\
\hline Cumulative $<40$ & 21.43 & 21.59 & 14.77 & 35.34 & 22.34 \\
\hline
\end{tabular}

When comparing percentage of students who received more than pass marks $(>40)$ for total marks, the significant reduction is noted in 2018 (64.66). But in 2019, it is equal to the range in 2015, 2016 and 2018 where PM was applied for the assessment. The reason for the significant reduction in 2018 could not be identified but it may be due to an unidentified problem in the conversion period. Though, all students have achieved pass marks in CA in 2018 and 2019 in NM, there is no effect to the total marks. Therefore it is clearly indicated that students did not use the advantage of NM to gain high marks for written examination. Since NM does not indicate any bad results in 2019, this study needs to be continued for at least another two three years to find the correct effect of applying NM.

\subsection{Students' Perception on Manual Drawing and its CA}

Data collected from the questionnaire survey are summarized in Table 3 is used for the analysis of students' perception for manual drawing and CA. Firstly, number of students responded under each questions and each rating are entered in an excel sheet and calculated to the percentage of students responded. Since there are few questions in a particular study area, average students' responses of each study area are calculated by taking the average of set of questions under the respective ratings. Calculation is expediently completed in the same excel sheet and presented in Table 6.

Table 5: Average

\begin{tabular}{|l|c|c|c|c|}
\hline \multirow{2}{*}{ Study Areas } & \multicolumn{4}{c|}{ Average Students' Responses \% } \\
\cline { 2 - 5 } & $\begin{array}{c}\text { Strongly } \\
\text { Agree }\end{array}$ & Agree & $\begin{array}{c}\text { Neither agree } \\
\text { nor disagree }\end{array}$ & Disagree \\
\hline Suitability of the adopted procedure & 42 & 46 & 8 & 4 \\
\hline Satisfaction of the classroom arrangement & 52 & 44 & 4 & 1 \\
\hline Interest of participation & 37 & 49 & 10 & 4 \\
\hline Achieving high performance & 35 & 47 & 12 & 5 \\
\hline Success of Instructors' feedback and the interaction & 45 & 51 & 4 & 6 \\
\hline
\end{tabular}

High percentages of responses are in the ratings of 'Strongly Agree' and 'Agree'. It indicates that majority of students have accepted that the use of NM is more supportive for their drawing practical. When adding students' responses (\%) of Agree and Strongly Agree together, it is found that more than $82 \%$ of students agreed the way of conducting total process of manual drawings and related CA. It is also found that, $96 \%$ of students agreed with the arrangement of the classroom and providing feedback supported for them to attend the manual drawing and CA. They highly agreed the new method (NM) of drawing practical and CA process for better participation and achieving high performance.

\section{CONCLUSIONS}

The results of this study is based on three evaluations considering the drawing marks alone received by the students, the total marks (drawing marks + marks for written questions) received by the students and the students' perceptions. New 
method (NM) implemented from 2018 has supported all students to obtain above pass marks for CA in manual drawing which has not supported to gain high marks in written examination. But students have agreed with the total process of NM as it supported for them to complete the assigned tasks and CA prior to the end examination by improving the manual drawing skills and to gain better performance. More than $82 \%$ of students highly agreed NM because of the procedure adopted, arrangement of the classroom and the feedback received from the Instructors. In previous study, it was proved that majority of students (71\%) who followed PM in 2017 gave opinion with preference for conducting the separate assessment for manual drawing [1]. They emphasized that attending drawing together with written questions caused struggling for time and concentrating on answering written questions in end examination [1]. In the same study, $83 \%$ of students preferred drawing assessment during the drawing practical. Hence, NM applied in 2018 and 2019 can be evaluated as students' friendly method of manual drawing combining with its assessments. Both groups of students in PM and NM held the same perception on conducting manual drawing practical and its continuous assessments.

\section{FURTHER STUDY}

It is recommend to carry out this study at least another two three years to get the proper view of the change made in 2018. Analysis based on two sets of marks (2018 and 2019) may not be sufficient to arrive with the correct findings as it is a new method.

\section{REFERENCES}

1. Abejehu, S.B. (2016). The practice of continuous assessment in primary schools: The case of Chagni, Ethiopia. Journal of Education and Practice, 7(13)

2. S. Sivakumar, N. Ranjithkumar \& S. Ragunathan, "Design and Development of Down Draft Wood Gasifier “, International Journal of Mechanical Engineering (IJME), Vol. 2, Issue 2, pp. 1-10

3. Airasian, P.W. (1991). Classroom Assessment. New York: McGraw-Hill

4. Baxter, A. (1997). Evaluating your students, Richmond Publishing, ISBN 84-2945067-X

5. Bayo, C.O. (2005). The basic of research methodology. Lagos: Kotleb Publishers

6. Biggs, J. \& Tang, C. 2007. Teaching for Quality Learning at University. 3rd Edition

7. Brown, S. (1999). Institutional strategies for assessment. In S. Brown \& A. Glasner (Eds.), Assessment matters in higher education: Choosing and using diverse approaches (pp. 3-13). Buckingham: SRHE and Open University Press

8. Coll, C., Rochera, M.J., Mayordomo, R.M. \& Naranjo, M. (2007), Continuous assessment and support for learning: an experience in educational innovation with ICT support in higher education, Electronic Journal of Research in Educational Psychology, N. 13 Vol 5 (3), pp: 783-804

9. Shehzad Zahir \& Jayedi Aman, "Evolution of Home Based Work ", International Journal of Civil Engineering (IJCE), Vol. 6, Issue 1,pp. 1-8

10. Educational quality in developing world (2003). Educational Review, December 5, (1)1, 3

11. Frederickson, N. (1992). Curriculum-based assessment: broadening the base. In Cline, T. (ed.), The assessment of special educational needs: International perspectives (pp. 147-169). London: Routledge

12. Gardner, J., Harlen, W., Hayward, L. \& Stobart, G. 2008. Changing Assessment Practice Process, Principles and Standards. Assessment Reform Group, UK 
13. Gonzalez, M.de la. $O \&$ Lopez, R. (2015). Impact of students' behavior on continuous assessment in Higher Education, pp 498-507. doi.org/10.1080/13511610.2015.1060882

14. S. R. Kushwah \& S. B. Naik, "Development of Pneumatic Roving End Opener “, International Journal of Mechanical and Production Engineering Research and Development (IJMPERD), Vol. 9, Issue 5, pp. 909-918

15. Huanyun Wang \& Chunhui Pan. 2013. Teaching reform of Engineering Graphics on the relationship between hand drawing and computer drawing, International Conference on Information, Business and Education Technology, 995-998

16. Kandamby, G.W.T.C. 2019. The formative assessments for building drawings', International Journal of Civil, Structural, Environmental and Infrastructure Engineering Research and Development, Vol. 9, Issue 1, 21-32

17. Mark D. Pavlak. 1991. A Study Comparing Basic Skills of Computer Assisted Drafting Students to Traditional Drafting Students, Old Dominion University ODU Digital Commons. https://digitalcommons.odu.edu/ots_masters_projects

18. McDowell, L., Sambell, K., Bazin, V., Penlington, R., Wakelin, D., Wickes, H., et al. (2005). Assessment for learning: Current practice exemplars from the centre for excellence in teaching and learning, guides for staff. Newcastle: University of Northumbria at Newcastle.

19. Mohammad Iqbal, Samiullah \& Aysha Anjum. 2017. Effect of Continuous Assessment Techniques on Students' Performance at Elementary level, Bulletin of Education and Research, Vol. 39, No. 1 pp. 91-100

20. Mweemba, G. \& Chilala, M. 2007. Piloting school-based continuous assessment at middle basic level: The Zambian approach, 13(1): $31-37$

21. Nxumalo, Z.F. (2007). The role of continuous assessment in primary school (M.Ed. Dissertation). Retrieved from http://uzspace.uzulu.ac.za/bitstream/handle/

22. Price, M., O'Donovan, B. \& Rust, C. 2007. Putting a social-constructivist assessment process model into practice: building the feedback loop into the assessment process through peer review. Innovations in Education and Teaching International, 44:2, pp. 143152

23. Rosario Hernandez. 2012. Does continuous assessment in higher education support student learning?, High Education, 64:489-502 DOI 10.1007/s10734-012-9506-7

24. Trotter, E. (2006). Student perceptions of continuous summative assessment. Assessment and Evaluation in Higher Education, $31(5), 505-521$

\section{APPENDIX}

Table 6: Students' Perceptions

\begin{tabular}{|l|c|c|c|c|}
\hline \multicolumn{1}{|c|}{ Questioned Area } & \multicolumn{3}{c|}{ Number of Students' Responses } \\
\cline { 2 - 5 } & $\begin{array}{c}\text { Strongl } \\
\text { y Agree }\end{array}$ & Agree & $\begin{array}{c}\text { Neither agree } \\
\text { nor disagree }\end{array}$ & $\begin{array}{c}\text { Disagre } \\
\text { e }\end{array}$ \\
\hline 1. Procedure & & & & 4 \\
\hline Applied better method for drawing practical & 20 & 43 & 12 & 5 \\
\hline Used drawing tools well & 34 & 35 & 5 & 1 \\
\hline Conducted CA properly for manual drawings & 45 & 30 & & 2 \\
\hline 2. Arrangement & & & & \\
\hline
\end{tabular}




\begin{tabular}{|c|c|c|c|c|}
\hline Provided good classroom arrangement & 51 & 24 & 2 & 1 \\
\hline Scheduled drawing practical ahead & 38 & 37 & 2 & 1 \\
\hline Received sketches in time for drawings & 32 & 41 & 5 & 0 \\
\hline \multicolumn{5}{|l|}{ 3. Participation } \\
\hline Received enough time for completion & 14 & 36 & 21 & 6 \\
\hline Received enough time for studying at home & 29 & 42 & 6 & 1 \\
\hline Studied Building Technology I module with interest & 38 & 36 & 2 & 2 \\
\hline Attended manual drawing with interest & 36 & 36 & 4 & 2 \\
\hline Attended CA in time & 27 & 41 & 7 & 3 \\
\hline Started manual drawing with interest & 27 & 38 & 8 & 5 \\
\hline \multicolumn{5}{|l|}{ 4. Performance } \\
\hline Developed drawing skills because of CA & 44 & 32 & 1 & 1 \\
\hline Received good marks for CA & 24 & 44 & 7 & 3 \\
\hline Utilized given time to complete the work & 26 & 36 & 10 & 5 \\
\hline Shared knowledge with peers & 44 & 31 & 3 & 0 \\
\hline Received good marks & 17 & 44 & 11 & 6 \\
\hline Learned final exam as CA completed early & 38 & 38 & 2 & 0 \\
\hline Improved subject knowledge because of manual drawing & 44 & 33 & 1 & 0 \\
\hline \multicolumn{5}{|l|}{ 5. Feedback and interaction } \\
\hline Used given instruction / clarification in the classroom & 32 & 44 & 2 & 0 \\
\hline Corrected drawings because of the given feedback & 41 & 35 & 2 & 0 \\
\hline Understood the mistakes & 44 & 33 & 1 & 0 \\
\hline Completed the corrections within the given time & 36 & 36 & 4 & 0 \\
\hline Encouraged to attend the work because of the feedback & 22 & 48 & 6 & 1 \\
\hline Developed good interaction with the instructors & 33 & 40 & 5 & 0 \\
\hline
\end{tabular}

